\title{
Immobilization of the iron on the surface of non-woven carbon fiber for use in a microbial fuel cell
}

\author{
Nichanan Phansroy $^{1} \cdot$ Yuji Aso $^{1} \cdot$ Sono Sasaki $^{1} \cdot$ Takashi Aoki $^{1} \cdot$ Hitomi Ohara $^{1}$
}

Received: 29 May 2016/ Accepted: 19 August 2016/Published online: 9 September 2016

(c) The Author(s) 2016. This article is published with open access at Springerlink.com

\begin{abstract}
Iron particles were immobilized onto non-woven carbon fiber via electroplating for use in a microbial fuel cell (MFC). Electroplating was performed under an applied voltage at a current of $0.2 \mathrm{~A}$ for 5,10 , and $15 \mathrm{~min}$. The scanning electron microscope (SEM) observations show that 5 min was not adequate for the particles to be immobilized, whereas 10 and 15 min of electroplating resulted in an adequate number of particles on the surface. To evaluate the strength of the binding of iron via electroplating on the surface of the fiber, the samples were washed with pure water and observed using an SEM. The 10 min electroplated sample has a larger surface area, which is suitable for the MFC anode, than the 15 min electroplated sample. According to X-ray photoelectron spectroscopy and $\mathrm{X}$-ray diffraction analysis, the peaks corresponded to those of $\mathrm{Fe}_{2} \mathrm{O}_{3}$, and the sample dipped into tannic acid shows the peaks of $\mathrm{Fe}_{3} \mathrm{O}_{4}$. The amount of biofilm of Shewanella oneidensis MR-1 was evaluated using crystal violet staining, and living bacteria were counted as colony forming units. Electroplated $\mathrm{Fe}_{2} \mathrm{O}_{3}$ and $\mathrm{Fe}_{3} \mathrm{O}_{4}$ were found to be effective for producing biofilm and immobilizing $S$. oneidensis MR-1.
\end{abstract}

Keywords Microbial fuel cell · Non-woven carbon fiber . Iron oxide $\cdot$ Shewanella oneidensis MR-1 - Electroplating

Hitomi Ohara

ohara@kit.ac.jp

1 Department of Biobased Materials Science, Kyoto Institute of Technology, 1 Hashigami-cho, Matsugasaki, Sakyo-ku, Kyoto 606-8585, Japan

\section{Introduction}

Respiration is one of the main energy aquisition processes of living microorganisms, and many living microorganisms depend on this efficient energy conversion mechanism. Electron donors and acceptors are required for respiration and heterotrophic microorganisms deliver the electrons, acting as a relatively strong reducing substance to $\mathrm{O}_{2}$, such as glucose. Glucose is oxidized to $\mathrm{CO}_{2}$, and $\mathrm{O}_{2}$ is reduced to $\mathrm{H}_{2} \mathrm{O}$. An inorganic compound including nitrogen or sulfur is used as an electron acceptor in the microorganism, and a metal-ion represented by iron or manganese is sometimes used. ATP is used to accumulate energy in living cells through this process. Alternatively, a microbial fuel cell (MFC) is used to convert the Gibbs free energy of redox reactions into electrical energy via movement of electrons and ions separately.

Shewanella oneidensis MR-1 is often used in an MFC. The processes of $S$. oneidensis MR-1 to transfer electrons to the electrode can roughly be classified into three categories. One process is called indirect electron transport, which concerns the mediator. The mediator having oxidation-reduction activity receives an electron from the cells and shuttles the electron between the electron acceptor and the electrode. In the case of $S$. oneidensis MR-1 secreting a derivative of quinone and flavin to the outside of the cells, it is possible to use these excretions as mediators [1-4]. Another process is called direct electron transport. $S$. oneidensis MR-1 is a metal-reducing and facultative anaerobic bacterium. This microorganism produces the outer membrane cytochromes called OmcA and MtrC at high density onto the cell surface via anaerobic cultivation. Unlike indirect electron transport involving mediator dispersion, an electron that is generated in the cell directly moves to the solid surface of the electrode through the 
outer membrane cytochromes [5-14]. S. oneidensis MR-1 produces electrically conductive pilus-like appendages [8] called bacterial nanowires [15] in direct response to the electron-acceptor limitation.

In addition, $S$. oneidensis MR-1 forms a biofilm of extracellular polysaccharide. The biofilms formed on the anode surface used for an MFC plays an important role in extracellular electron transfer. The relation between the cell density and the power generation output using the $S$. loihica PV-4 strain was previously studied [16]. The study found that the current density was hardly changed with increasing microbial density in microbial suspension. This result shows that the biofilm formed on the electrode surface contributes to current generation and becomes the main current generation source. By comparing the power generation output between the PV-4 strain formed biofilm and the S. oneidensis MR-1 added mediator, the current density and the coulomb efficiency of strain PV-4 were found to be higher than those of $S$. oneidensis MR-1 [5]. This result shows the electron transfer to the electrode via the mediator is limited by the diffusion of the mediator [17]. A biofilm can facilitate the bacterial electron transfer efficiency in an MFC primarily due to the much higher biomass densities and higher bacterial viability caused by anode respiration [8, 18-20]. From these results, in an MFC, the advantage of the formation of a biofilm on the electrode is understood to be the large specific surface area for the electrogenic microorganism. Although the electron is generated from the cell but the biofilm, these reports do not show the number of living cells for the given amount of the biofilm.

Metal-reducing bacteria such as $S$. oneidensis MR-1 have been studied to understand their ability to recognize the surface of iron oxide and to initiate extracellular electron transfer to an attached iron oxide as a terminal process in its metabolism [21, 22]. Moreover, iron oxide may promote the biofilm formation of $S$. oneidensis MR-1 onto an electrode [23].

Non-woven carbon fibers (NWCFs) are suitable for use as electrodes of MFCs because they have good conductivity, a large surface area, and relatively low cost. NWCFs have been used in many studies. For example, an ITO glass slide coated with carbon graphite fiber used as the anode showed much higher current density than the non-coated slide when S. loihica PV-4 was used in an MFC [24]. In another report, an NWCF electrode for MFCs interposed between iron nets showed 1.5 times higher power density compared with that for MFCs without the iron nets [25]. In another report, NWCFs were used in a type of MFCs called a Slalom-flow cassette-electrode microbial fuel cell [26]. As mentioned above, the development of an NWCF coated with ferric oxide is important to improve the current density. However, there are few reports regarding the coating technique, except for a chemical vapor deposition technique [27]. However, the chemical vapor deposition technique requires a large-scale apparatus and is an expensive method. As a result, another method to immobilize iron oxide onto NWCFs is necessary.

Therefore, in this study, iron oxide immobilized NWCFs were developed using an electroplating technique. The redox state and crystal structure of iron oxide particles immobilized onto NWCFs using this electroplating technique were determined using X-ray analysis. Moreover, the amounts of biofilm and the number of living cells of $S$. oneidensis MR-1 on this electrode were quantified.

\section{Experimental}

\section{Materials and chemicals}

Non-woven carbon fiber (NWCF) firming polyacrylonitrile was specially made by Japan Vilene Co., (Tokyo, Japan). The lengths of fibers are about $50 \mathrm{~mm}$ and the diameter is about $7 \mu \mathrm{m}$, and the mass per unit area of NWCF is $100 \mathrm{~g} /$ $\mathrm{m}^{2}$. Iron (II) sulfate heptahydrate $\left(\mathrm{FeSO}_{4} \cdot 7 \mathrm{H}_{2} \mathrm{O}\right)$ as electrolyze solution and crystal violet were purchased from Nacalai Tesgue, Inc (Kyoto, Japan). Saponin (Practical grade, MP Biomedicals LLC, France) and tannic acid were purchased from Wako Pure Chemical Industries, Ltd. (Osaka, Japan). S. oneidensis MR-1 (ATCC 700550) was obtained from the American Type Culture Collection.

\section{Iron plating on NWCF}

A $1 \mathrm{~g}$ of $\mathrm{FeSO}_{4} \cdot 7 \mathrm{H}_{2} \mathrm{O}$ was dissolved in $100 \mathrm{~mL}$ of distilled water and used as electrolyze of electroplating method. NWCF is cut into $3 \times 5 \mathrm{~cm}$, then immersed in the beaker and connected to negative and positive side of power supply (SN-5B, Kenis Ltd., Osaka, Japan). The NWCFs were adjusted the distance at $6 \mathrm{~cm}$ and depth at $3.5 \mathrm{~cm}$. Electroplates were carried out under current at $0.2 \mathrm{~A}$ $(22 \mathrm{~V})$ for 5, 10 and $15 \mathrm{~min}$. After electroplating, the samples were washing with pure water (using about $50 \mathrm{~mL}$ ) till the $\mathrm{pH}$ became neutral promptly, because in the process of electroplating, the $\mathrm{H}_{2} \mathrm{SO}_{4}$ is produced in the solution and soaked in the NWCF. This causes $\mathrm{pH}$ decrease which inhibits the growth of microorganism for MFC. The samples were cut in half $(1.5 \times 5 \mathrm{~cm})$ and one piece was dried at room temperature. To evaluate how strong the iron was plated on the surface of the fiber, another piece was put in $150 \mathrm{~mL}$ of pure water and stirred with magnetic stirrer at $250 \mathrm{rpm}$ for $24 \mathrm{~h}$, then dried at room temperature.

\section{Tannic acid treatment}

The $1.7 \mathrm{~g}$ of tannic acid is dissolved in $50 \mathrm{~mL}$ of distilled water and poured to petri dish. The iron plated for $10 \mathrm{~min}$ 
on NWCF $(1.5 \times 5 \mathrm{~cm})$ was cut in half and dipped in petri dish containing tannic acid solution for $24 \mathrm{~h}$. Then the sample was washed with $50 \mathrm{~mL}$ of pure water and dried at room temperature.

\section{Biofilm growth on non-woven carbon fiber}

Shewanella oneidensis MR-1 was first grown aerobically in Luria-Bertani (LB) medium at $30{ }^{\circ} \mathrm{C}$ for $18 \mathrm{~h}$ preparing pre-culture. The pre-culture was inoculated in $5 \mathrm{~mL}$ of flesh LB medium in testing tube to $\mathrm{OD}_{600}=0.1$ and incubated with shaking at $120 \mathrm{rpm}$ at $30{ }^{\circ} \mathrm{C}$ for $24 \mathrm{~h}$. The iron plated NWCF of the dimensions of $1 \times 1 \mathrm{~cm}$ were soaked into the culture then incubated with shaking at $120 \mathrm{rpm}$ at $30{ }^{\circ} \mathrm{C}$ for $24 \mathrm{~h}$. After incubation, samples were washed in $0.85 \mathrm{wt} \%$ of $\mathrm{NaCl}$ solution. As a control, noninoculated LB medium and non-iron plated NWCF were used.

\section{Analytical methods}

Observations of the phase of iron plated NWCF were carried out by scanning electron microscope (SEM) (JSM6510A, JEOL Ltd., Tokyo, Japan) operated at $15 \mathrm{kV}$. Surface elemental analysis of iron plated NWCF was performed using X-ray photoelectron spectroscopy (XPS) (JPS-90MX, JEOL Ltd.). An Mg K $\alpha$ radiation with voltage of $8 \mathrm{kV}$ and current of $5 \mathrm{~mA}$ were applied. The phase structures of iron plated NWCF were measured by X-ray diffraction analysis (XRD) (RINT $2500 \mathrm{~V}$, Rigaku Co., Tokyo, Japan) and were scanned from $10^{\circ}$ to $100^{\circ}$ in 2 theta using $\mathrm{Cu} \mathrm{K} \alpha$ radiation.

For SEM analysis, the samples incubated with $S$. oneidensis MR-1 were fixed with $1 \mathrm{v} / \mathrm{v} \%$ glutaraldehyde in $0.1 \mathrm{M}$ phosphate buffer $(\mathrm{pH} 7.2)$ for $30 \mathrm{~min}$ at $4{ }^{\circ} \mathrm{C}$. Subsequently, they were dehydrated in graded ethanol series $(50,60,70,80,90,95$ and $100 \mathrm{v} / \mathrm{v} \%)$. After dehydration, the samples were put in $n$-butanol followed by frozen at $-8{ }^{\circ} \mathrm{C}$ and dried under vacuum. The dried samples coated with platinum were examined using SEM.

To evaluate the biofilm formation, the samples incubated with $S$. oneidensis MR-1 were fixed with $2.5 \mathrm{~mL}$ of methanol for $20 \mathrm{~min}$ and then were stained with $2.5 \mathrm{~mL}$ of $0.75 \mathrm{w} / \mathrm{v} \%$ crystal violet $[28,29]$. To eliminate residual crystal violet, the stained samples were washing under running tab water. After the stained samples were air-dried, crystal violet absorbed on samples was dissolved in $2.5 \mathrm{~mL}$ of $33 \mathrm{v} / \mathrm{v} \%$ acetic acid. The absorbance of crystal violet eluted was measured at $600 \mathrm{~nm}[28,29]$.

To evaluate the viable bacteria count, the samples were washing with $0.1 \mathrm{M}$ PBS buffer ( $\mathrm{pH} 7.2)$ and then vortexed in $1 \mathrm{~mL}$ of $0.5 \mathrm{w} / \mathrm{v} \%$ saponin solution for $2 \mathrm{~min}$. Serial tenfold dilutions of the suspension obtained were prepared and then $100 \mu \mathrm{l}$ of dilutants were plated onto LB agar plates. After incubation for $48 \mathrm{~h}$ at $30^{\circ} \mathrm{C}$, the number of colonies on the agar plates was measured and then colony forming unit (CFU) was calculated [30, 31].

\section{Results and discussion}

Photographs of an iron plated NWCF produced after electroplating for $10 \mathrm{~min}$ for the subsequent processing stages are shown in Fig. 1a-c. After washing with pure water, the surface of the NWCF exhibits a black color (Fig. 1a); then, after $24 \mathrm{~h}$ of air drying, the surface of the NWCF turns from black to brown (Fig. 1b). Finally, the change of the surface following the tannic acid treatment presented in Fig. 1c shows that the color of the particles deposited on the NWCF changed from brown to black. This color change indicates that plated iron changed to $\gamma$ -
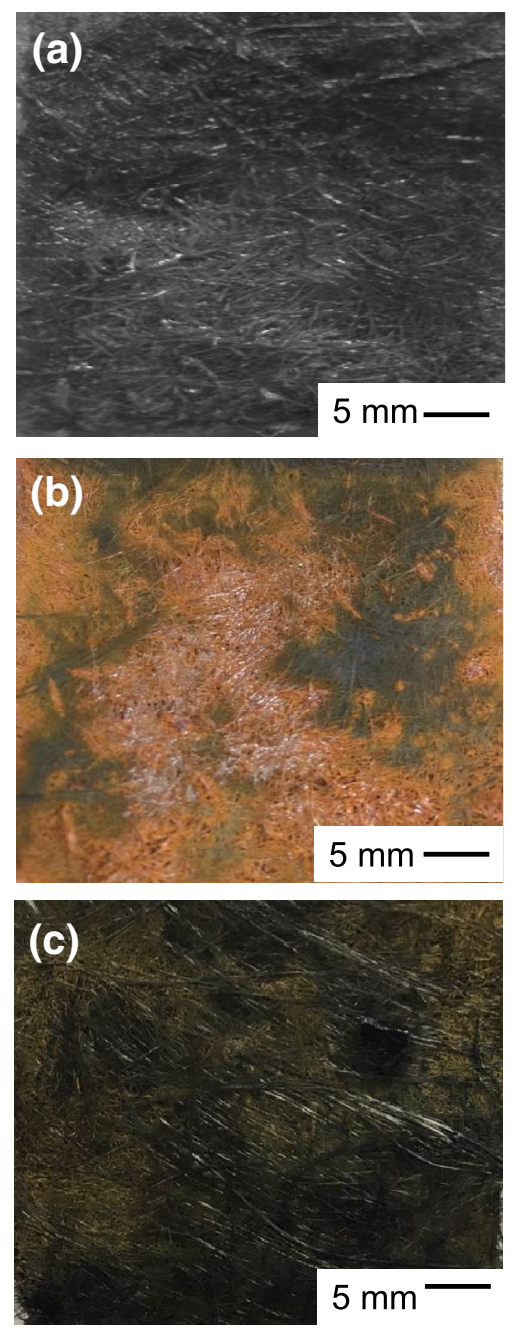

Fig. 1 Photograph of iron plated NWCF for $10 \mathrm{~min}$. a Washing with pure water, no-drying, b after $24 \mathrm{~h}$, drying and c tannic acid treatment, after drying 
$\mathrm{FeOOH}, \alpha-\mathrm{Fe}$, and $\gamma-\mathrm{Fe}_{2} \mathrm{O}_{3}$, characterized brown color and called lepidocrocite or iron oxide hydroxide, iron, and maghemite, or iron (III) oxide, respectively, during the drying process. In addition, the $\gamma$-FeOOH, $\alpha-\mathrm{Fe}$, and $\gamma$ $\mathrm{Fe}_{2} \mathrm{O}_{3}$ were reduced to $\mathrm{Fe}_{3} \mathrm{O}_{4}$, characterized by the black color and called magnetite or iron (II, III) oxide, due to the tannic acid treatment. Furthermore, this is confirmed by XRD analysis. To our knowledge, studies of the effect of iron on biofilm formation of $S$. oneidensis involve only pure iron [32]; we were unable to find a study that compared several iron compounds for biofilm formation. Hence, the results of this study are interesting.

\section{Morphology of iron plated NWCF}

SEM analysis showed that the surface of the NWCF appears smooth (Fig. 2a). In contrast, the results of electroplating at different times $(5,10$, and $15 \mathrm{~min})$ are shown in Fig. 2b-d. The electroplating for 5 min was not sufficient to coat iron onto the NWCF (Fig. 2b). In contrast, the electroplating for $15 \mathrm{~min}$ resulted in abundant deposition of iron (Fig. 2d). As shown in Fig. $2 \mathrm{c}$ and $\mathrm{d}$, the particles of iron were closely packed on the surface of the NWCF, resulting in a large surface area. Such a large surface area is advantageous to electron transport from the cell to the anode.

The results of the stability test of plated iron on the NWCF are shown in Fig. 3. As shown in Fig. 3a, particle aggregates were distributed throughout the NWCF, and each NWCF was enclosed with particle sheets (Fig. 3b). The characteristics of the particles following electroplating for $10 \mathrm{~min}$ were better than those following electroplating for $15 \mathrm{~min}$ because of the large surface area suitable for application to an MFC. Thus, we choose the case of performing iron electroplating at $0.2 \mathrm{~A}$ for $10 \mathrm{~min}$.
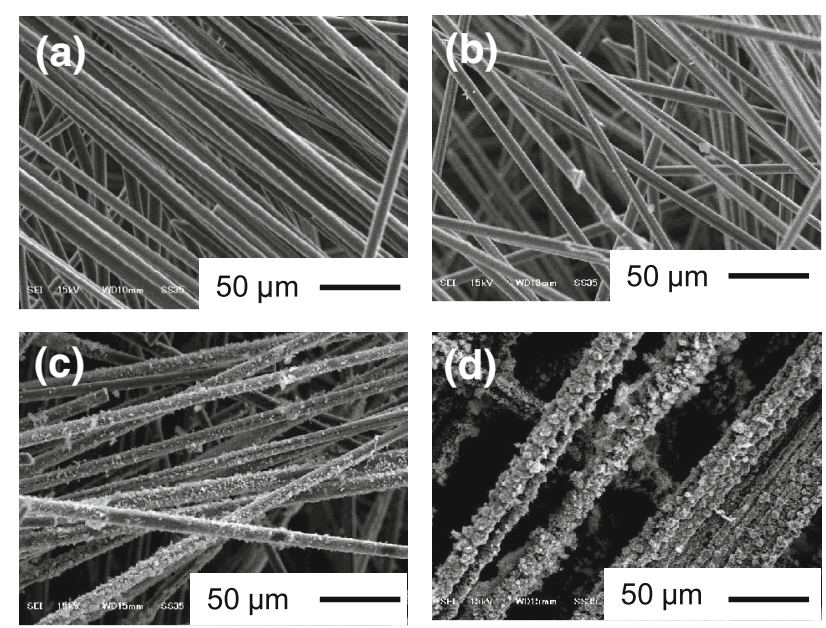

Fig. 2 SEM images of a NWCF. Iron electroplated for b 5 min c $10 \mathrm{~min}$ and $\mathbf{d} 15 \mathrm{~min}$ after washing with $50 \mathrm{~mL}$ water

\section{Surface elemental analysis of an iron plated NWCF}

To examine the composition of iron on the NWCF at different plating times, XPS spectra of $\mathrm{Fep}_{3 / 2}$, O1s, and C1s are shown in Fig. 4. The sample electroplated for $5 \mathrm{~min}$ shows peaks of 718, 538, and $290.8 \mathrm{eV}$ for Fep $3 / 2$ (Fig. 4a), O1s (Fig. 4b), and C1s (Fig. 4c), respectively, while the corresponding peaks appeared at 715, 533-534, and $289 \mathrm{eV}$, respectively, for the samples electroplated for 10 and $15 \mathrm{~min}$. This observation suggests that the initial layer of iron electroplated onto the NCWF has a different structure from the iron of the upper layer.

\section{The phase structure of iron plated NWCF}

The XRD profiles for the iron coated NWCF for 5 and 10 min of electroplating are shown in Fig. 5a and b, respectively. The diffraction peak appearing at the $2 \theta$ value of $25.54^{\circ}$ is the characteristic reflection of carbon graphite crystals in the composite. The characteristic peaks of an $\alpha$ Fe crystal were observed for the sample electroplated for $5 \mathrm{~min}$; the assignment was determined on the basis of the Crystallography Open Database (9013415). Additional peaks of $\gamma-\mathrm{FeOOH}$ and $\gamma-\mathrm{Fe}_{2} \mathrm{O}_{3}$ were presented for the sample electroplated for $10 \mathrm{~min}$, as determined on the basis of the Crystallography Open Database (9009154) and (9006317), respectively. These peaks may be caused by the electroplating process of iron on the NWCF: first, the
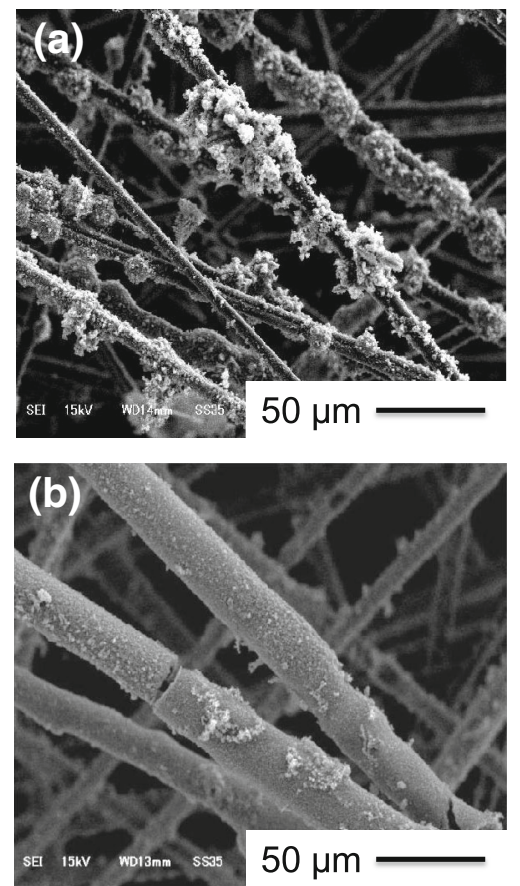

Fig. 3 SEM images of iron particle stability test stilled in $150 \mathrm{~mL}$ water for $24 \mathrm{~h}$, electroplated for a $10 \mathrm{~min}$ and b $15 \mathrm{~min}$ 
(a)

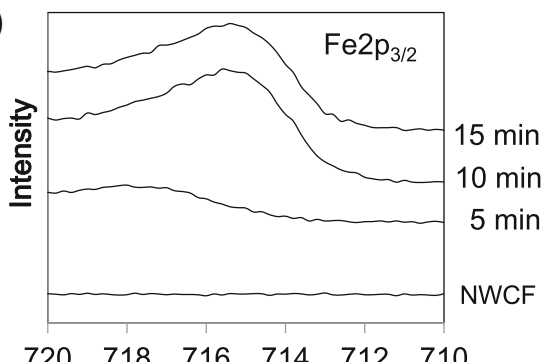

(b)

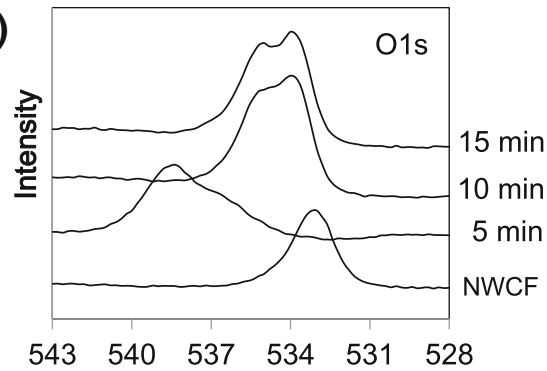

(c)

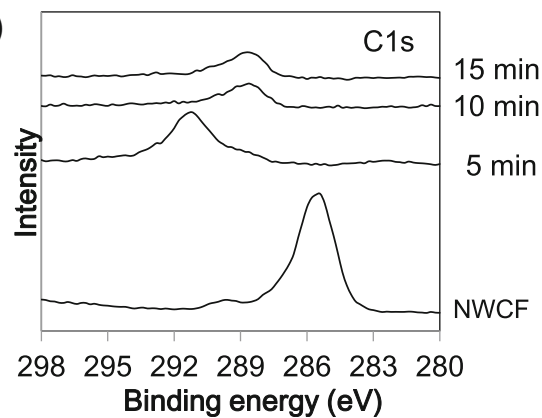

Fig. 4 XPS in the a Fe2 $\mathrm{p}_{3 / 2}, \mathbf{b} \mathrm{O} 1 \mathrm{~s}$ and $\mathbf{c} \mathrm{C} 1 \mathrm{~s}$ regions for NWCF, and iron plated NWCF of different times $(5,10$ and $15 \mathrm{~min})$

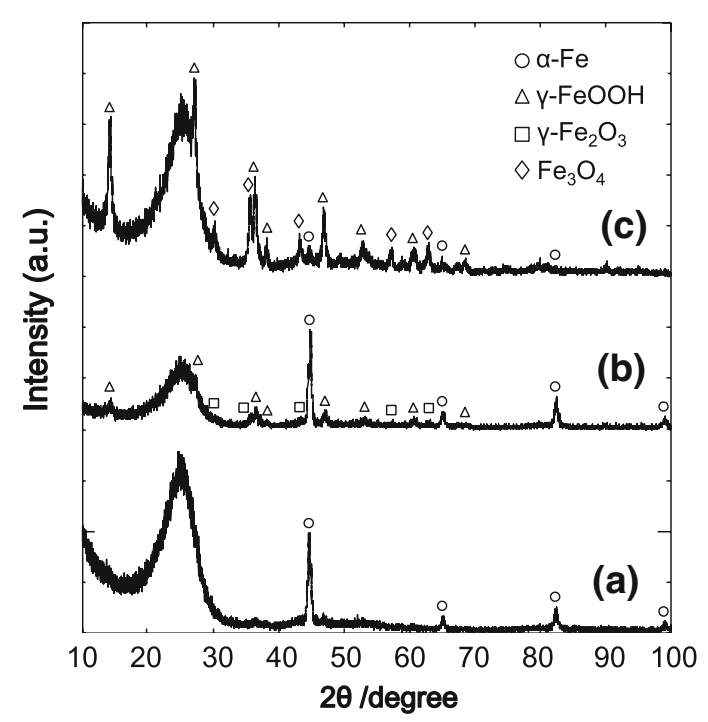

Fig. 5 X-ray diffraction patterns of iron plated NWCF for a 5 min, b $10 \mathrm{~min}$ and $\mathbf{c}$ after tannic acid treatment for $24 \mathrm{~h}$. The symbols; $\alpha-$ $\mathrm{Fe}$ (circle), $\gamma$-FeOOH (triangle), $\gamma-\mathrm{Fe}_{2} \mathrm{O}_{3}$ (square), $\mathrm{Fe}_{3} \mathrm{O}_{4}$ (diamond)
NWCF was covered with $\alpha-\mathrm{Fe}$, and then the layers of $\gamma$ $\mathrm{FeOOH}$ and $\gamma-\mathrm{Fe}_{2} \mathrm{O}_{3}$ were deposited.

Clearly, the diffraction peaks of $\gamma-\mathrm{FeOOH}$ and $\gamma-\mathrm{Fe}_{2} \mathrm{O}_{3}$ appeared for the sample electroplated for $10 \mathrm{~min}$ (Fig. 5b), which is because of the increase of the amount of immobilized iron with the electroplating time. Furthermore, Fig. 5c shows the XRD pattern of the iron plated NWCF after treatment with tannic acid for $24 \mathrm{~h}$. The figure shows that all the diffraction peaks can be assigned to $\gamma-\mathrm{FeOOH}$, $\alpha-\mathrm{Fe}$, and $\mathrm{Fe}_{3} \mathrm{O}_{4}$ (COD 9005840). In other words, $\gamma-\mathrm{Fe}_{2} \mathrm{O}_{3}$ tranformed to $\mathrm{Fe}_{3} \mathrm{O}_{4}$ due to the tannic acid treatment.

\section{Effect of iron oxide on the biofilm formation by $S$. oneidensis MR-1}

Using the NWCF and the iron plated NWCF, the biofilm formation by $S$. oneidensis MR-1 was demonstrated over $24 \mathrm{~h}$ with shaking. Expectedly, the biofilm formation by $S$. oneidensis MR-1 was observed on iron plated NWCF after $24 \mathrm{~h}$ of incubation. However, no biofilm formation was observed on the NWCF (Fig. 6). It has been reported that $S$. oneidensis MR-1 exhibits an affinity to iron oxide [22, 23]. These results suggest that the iron oxide on the NWCF promoted biofilm formation by $S$. oneidensis MR-1.

To quantitatively evaluate the biofilm formation, the NWCF and the iron plated NWCF after $24 \mathrm{~h}$ of incubation with $S$. oneidensis MR-1 were assayed using crystal violet staining. The respective absorbance values observed via the assay with the NWCF after $24 \mathrm{~h}$ of incubation $\left(A_{600}=0.655\right)$ were compared with those for the iron $\left(\mathrm{Fe}_{2} \mathrm{O}_{3}\right.$ and $\left.\mathrm{Fe}_{3} \mathrm{O}_{4}\right)$ plated NWCF after $24 \mathrm{~h}$ of incubation $\left(A_{600}=1.309\right.$ and 1.205, respectively) (Fig. 7). This result indicated that biofilm formation by $S$. oneidensis MR-1 on the NWCF grown enough after $24 \mathrm{~h}$ of incubation. The iron plated NWCF showed a higher amount of biofilm than NWCF after $24 \mathrm{~h}$ of incubation. This result is in good agreement with the result of the SEM analysis. Compared with the case of NWCF, the amount of biofilm on the iron plated NWCF was approximately twofold higher after $24 \mathrm{~h}$ of incubation. This result may be due to the higher surface area of the iron plated NWCF compared with the bare NWCF, thereby enabling more $S$. oneidensis MR-1 to attach. In fact, iron oxide has a hollow structure and provides a high surface area. This finding suggests that iron oxide provides not only affinity with $S$. oneidensis MR-1 but also a high surface area with the NWCF.

To understand the cell viability on the NWCF, the CFU was measured. The respective $\mathrm{CFU}$ increased when assayed with the iron $\left(\mathrm{Fe}_{2} \mathrm{O}_{3}\right.$ and $\left.\mathrm{Fe}_{3} \mathrm{O}_{4}\right)$ plated NWCF $\left(2.77 \times 10^{6} / \mathrm{mL}\right.$ and $2.675 \times 10^{6} / \mathrm{mL}$, respectively) compared with that with the bare NWCF $\left(2 \times 10^{6} / \mathrm{mL}\right)$ (Fig. 8). In addition, the amount of biofilm formed was 

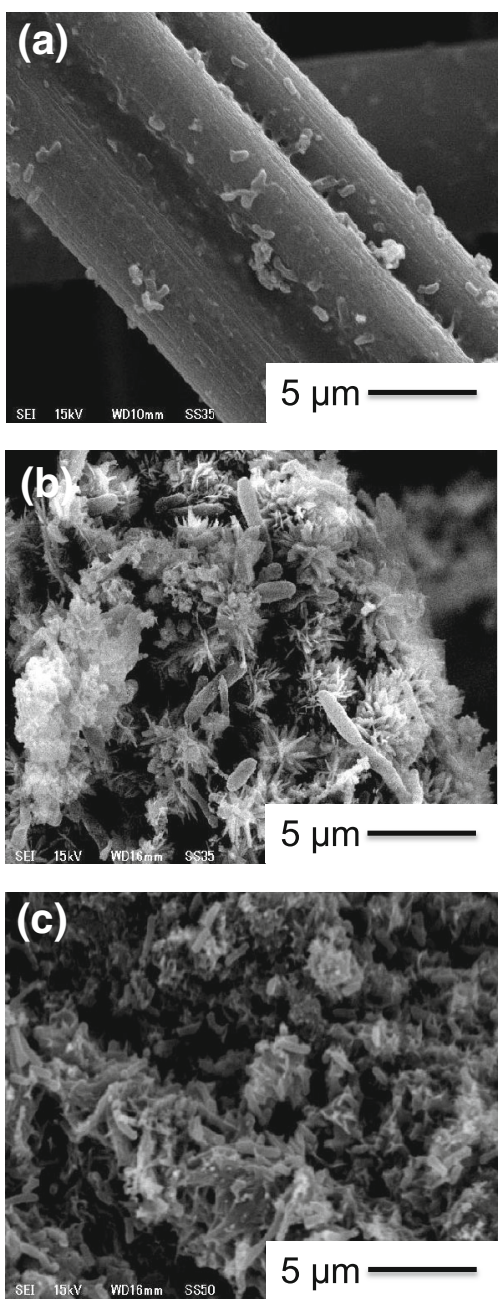

Fig. 6 SEM images of the attachment of $S$. oneidensis MR-1 on a the NWCF, $\mathbf{b}$ the $\mathrm{Fe}_{2} \mathrm{O}_{3}$ plated NWCF and $\mathbf{c}$ the $\mathrm{Fe}_{3} \mathrm{O}_{4}$ plated NWCF

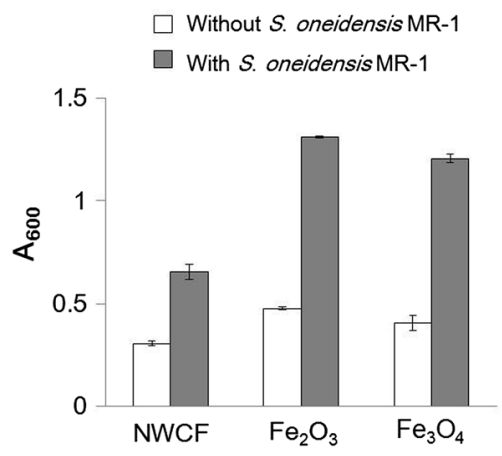

Fig. 7 Quantification of biofilm formation on NWCF, $\mathrm{Fe}_{2} \mathrm{O}_{3}$ and $\mathrm{Fe}_{3} \mathrm{O}_{4}$ plated NWCF after $24 \mathrm{~h}$ incubations. The amount of biofilm was evaluated using crystal violet staining. The absorbance of crystal violet eluted was measured at $600 \mathrm{~nm}$ after washing with saline solution for $15 \mathrm{~min}$. This assay was performed in duplicate, and the mean value is presented with error bars representing standard deviations from the mean. White bars, without $S$. oneidensis MR-1 (control); gray bars, with $S$. oneidensis MR-1

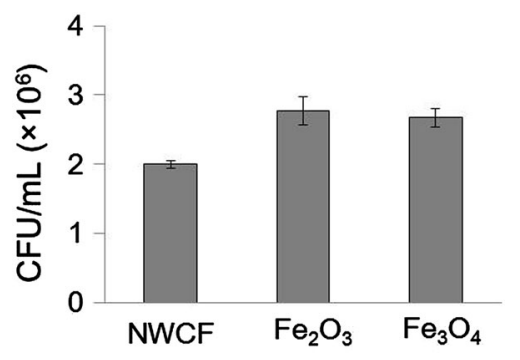

Fig. 8 CFU of S. oneidensis MR-1 on NWCF, $\mathrm{Fe}_{2} \mathrm{O}_{3}$ and $\mathrm{Fe}_{3} \mathrm{O}_{4}$ plated NWCF after $24 \mathrm{~h}$ incubations. This assay was performed in duplicate and the mean value is presented with error bars representing standard deviations from the mean

approximately 1.385 times that on the bare NWCF. This result is in good agreement with the results of SEM analysis and crystal violet staining.

Taken together, it was concluded that almost all the biofilm was formed after $24 \mathrm{~h}$ of incubation and that iron oxide promotes biofilm formation by $S$. oneidensis MR-1 and results in a high surface area. Electroplated iron oxide was immobilized onto the NWCF with sufficient strength, thereby enabling the use of the coated NWCF as an electrode. The results presented herein provide a pathway to a novel immobilization technique for depositing iron particles onto NWCFs for use in MFCs.

Acknowledgments The non-woven carbon fiber was kindly provided by Japan Vilene Company Ltd.

Open Access This article is distributed under the terms of the Creative Commons Attribution 4.0 International License (http:// creativecommons.org/licenses/by/4.0/), which permits unrestricted use, distribution, and reproduction in any medium, provided you give appropriate credit to the original author(s) and the source, provide a link to the Creative Commons license, and indicate if changes were made.

\section{References}

1. Hau, H.H., Gralnick, J.A.: Ecology and Biotechnology of the Genus Shewanella. Annu. Rev. Microbiol. 61, 237-258 (2007)

2. Gralnick, J.A., Newman, D.K.: Extracellular respiration. Mol. Microbiol. 65, 1-11 (2007)

3. Marsili, E., Baron, D.B., Shikhare, I.D., Coursolle, D., Gralnick, J.A., Bond, D.R.: Shewanella secretes flavins that mediate extracellular electron transfer. Proc. Natl. Acad. Sci. USA 105, 3968-3973 (2008)

4. Shi, L., Squire, T.C., Zachara, J.M., Fredrickson, J.K.: Respiration of metal (hydr)oxides by Shewanella and Geobacter: a key role for multihaem c-type cytochromes. Mol. Microbiol. 65, 12-20 (2007)

5. Newton, G.J., Mori, S., Nakamura, R., Hashimoto, K., Watanabe, K.: Analyses of current-generating mechanisms of Shewanella loihica PV-4 and Shewanella oneidensis MR-1 in microbial fuel cells. Appl. Environ. Microbiol. 75, 7674-7681 (2009) 
6. Lovely, D.R.: The microbe electric: conversion of organic mater to electricity. Curr. Pipn. Biotechnol. 19, 564-571 (2008)

7. Fredrickson, J.K., Romine, M.F., Beliaev, A.S., Auchtung, J.M., Driscoll, M.E., Gardner, T.S., Nealson, K.H., Osterman, A.L., Pinchuk, G., Reed, J.L., Rodionov, D.A., Rodrigues, J.L., Saffarini, D.A., Serres, M.H., Spormann, A.M., Zhulin, I.B., Tiedje, J.M.: Towards environmental system biology of Shewanella. Nat. Rev. Microbiol. 6, 592-603 (2008)

8. Gorby, Y.A., Yanina, S., McLean, J.S., Rosso, K.M., Moyles, D., Dohnalkova, A., Beveridge, T.J., Chang, I.S., Kim, B.H., Kim, K.S., Culley, D.E., Reed, S.B., Romine, M.F., Saffarini, D.A., Hill, E.A., Shi, L., Elias, D.A., Kennedy, D.W., Pinchuk, G., Watanabe, K., Ishii, S., Logan, B., Nealson, K.H., Fredrickson, J.K.: Electrically conductive bacterial nanowires produced by Shewanella oneidensis strain MR-1 and other microorganisms. Proc. Natl. Acad. Sci. USA 103, 11358-11363 (2006)

9. Kim, H.J., Park, H.S., Hyun, M.S., Chang, I.S., Kim, M., Kim, B.H.: A mediator-less microbial fuel cell using a metal reducing bacterium, Shewanella putrefaciens. Enzyme Microb. Technol. 30, 145-152 (2002)

10. Wigginton, N.S., Rosso, K.M., Hochella, M.F.: Mechanisms of electron transfer in two decaheme cytochromes from a metalreducing bacterium. J. Phys. Chem. B 111, 12857-12864 (2007)

11. Hartshorne, R.S., Jepson, B.N., Clarke, T.A., Field, S.J., Fredrickson, J., Zachara, J., Shi, L., Butt, J.N., Richardson, D.J.: Characterization of Shewanella oneidensis MtrC: a cell-surface decaheme cytochrome involved in respiratory electron transport to extracellular electron acceptors. J. Biol. Inorg. Chem. 12, 1083-1094 (2007)

12. Wigginton, N.S., Rosso, K.M., Lower, B.H., Shi, L., Hochella, M.F.: Electron tunneling properties of outer-membrane decaheme cytochromes from Shewanella oneidensis. Geochim. Cosmochim. Acta 71, 543-555 (2007)

13. Field, S.J., Dobbin, P.S., Cheesman, M.R., Watmough, N.J., Thomson, A.J., Richardson, D.J.: Purification and magneto-optical spectroscopic characterization of cytoplasmic membrane and outer membrane multiheme c-type cytochromes from Shewanella frigidimarina NCIMB400. J. Biol. Chem. 275, 8515-8522 (2000)

14. Clarke, T.A., Edwards, M.J., Gates, A.J., Hall, A., White, G.F., Bradley, J., Reardon, C.L., Shi, L., Beliaev, A.S., Marshall, M.J., Wang, Z., Watmough, N.J., Fredrickson, J.K., Zachara, J.M., Butt, J.N., Richardson, D.J.: Structure of a bacterial cell surface decaheme electron conduit. Proc. Natl. Acad. Sci. USA 108, 9384-9389 (2011)

15. Reguera, G., McCarthy, K.D., Mehta, T., Nicoll, J.S., Tuominen, M.T., Lovley, D.R.: Extracellular electron transfer via microbial nanowires. Nature 435, 1098-1101 (2005)

16. Nakamura, R., Kai, F., Okamoto, A., Newton, G.J., Hashimoto, K.: Self-constructed electrically conductive bacterial networks. Angew. Chem. Int. Ed. Engl. 48, 508-511 (2009)

17. Torres, C.J., Marcus, A.K., Lee, H.S., Parameswaran, P., Krajmalnik-Brown, R., Rittmann, B.E.: A kinetic perspective on extracellular electron transfer by anode-respirating bacteria. FEMS Microbiol. Rev. 34, 3-17 (2010)
18. Bakken, L.R., Olsen, R.A.: Buoyant densities and dry-matter contents of microorganisms: conversion of a measured biovolume into biomass. Appl. Environ. Microbiol. 45, 1188-1195 (1983)

19. Read, S.T., Dutta, P., Bond, P.L., Keller, J., Rabaey, K.: Initial development and structure of biofilm on microbial fuel cells anodes. BMC Microbiol. 10, 98 (2010)

20. O'Toole, G., Kaplan, H.B., Kolter, R.: Biofilm formation as microbial development. Annu. Rev. Microbiol. 54, 49-79 (2000)

21. Meitl, L.A., Eggleston, C.M., Colberg, P.J.S., Khare, N., Reardon, C.L., Shi, L.: Electrochemical interaction of Shewanella oneidensis MR-1 and its outer membrane cytochromes OmcA and MtrC with hematite electrodes. Geochim. Cosmochim. Acta 73, 5292-5307 (2009)

22. Bose, S., Hochella Jr., M.F., Gorby, Y.A., Kennedy, D.W., Mccready, D.E., Madden, A.S., Lower, B.H.: Bioreduction of hematite nanoparticles by the dissimilatory iron reducing bacterium Shewanella oneidensis MR-1. Geochim. Cosmochim. Acta 73, 962-976 (2009)

23. Yu, Y.Y., Chen, H., Yong, Y.C., Kim, D.H., Song, H.: Conductive artificial biofilm dramatically enhances bioelectricity production in Shewanella-inoculated microbial fuel cell. Chem. Commun. 47, 12825-12827 (2011)

24. Zhao, Y., Watanabe, K., Nakamura, R., Mori, S., Liu, H., Ishii, K., Hashimoto, K.: Three-dimensional conductive nanowire networks for maximizing anode performance in microbial fuel cells. Chem. Eur. J. 16, 4982-4985 (2010)

25. Yu, J., Tang, Y.: Coating-type three-dimensional acetate-driven microbial fuel cells. J. Biosci. Bioeng. 120, 135-139 (2015)

26. Miyahara, M., Hashimoto, K., Watanabe, K.: Use of cassetteelectrode microbial fuel cell for wastewater treatment. J. Biosci. Bioeng. 115, 176-181 (2013)

27. Kim, J.R., Min, B., Logan, B.E.: Evaluation of procedures to acclimate a microbial fuel cell for electricity production. Appl. Microbiol. Biotechnol. 68, 23-30 (2005)

28. Stepanovic, S., Cirkovic, I., Ranin, L., Vlahovic, M.S.: Biofilm formation by Salmonella spp. and Listeria monocytogenes on plastic surface. Lett. Appl. Microbiol. 38, 428-432 (2004)

29. Victoria, O., Tajudeen, O.I.: Crystal violet binding assay for assessment of biofilm formation by Listeria monocytogenes and Listeria spp on wood, steel and glass surface. Glob. Vet. 6, 6-10 (2011)

30. Sivakumar, P.M., Prabhawathi, V., Neelakadan, R., Doble, M.: Chacone coating on cotton cloth-an approach to reduce attachment of live microbes. Biomater. Sci. 2, 990-995 (2014)

31. Traczewska, T.M., Sitarska, M.: Deterioration of polymeric materials exposed to metabolic activity of microorganisms in a water distribution system. Pol. J. Environ. Stud. 22, 257-266 (2013)

32. Xu, S., Liu, H., Schaller, R., Jiao, J., Chaplen, F.: Enhanced performance and mechanism study of microbial electrolysis cells using $\mathrm{Fe}$ nanoparticle-decorated anodes. Appl. Microbial. Biotechnol. 93, 871-880 (2012) 